\title{
Rheumatoid arthritis is an autoimmune disease caused by periodontal pathogens
}

This article was published in the following Dove Press journal:

International Journal of General Medicine

23 May 2013

Number of times this article has been viewed

\section{Mesut Ogrendik}

Division of Physical Therapy and Rheumatology, Nazilli State Hospital, Nazilli, Turkey
Correspondence: Mesut Ogrendik Altintas District, Kocacami Street, Erten Kocabay Apartment Number 2; Kat: 6, 09800, Nazilli-Aydin, Turkey Tel +902563120000

Email neml82@hotmail.com

\begin{abstract}
A statistically significant association between periodontal disease (PD) and systemic diseases has been identified. Rheumatoid arthritis (RA), which is a chronic inflammatory joint disease, exhibits similar characteristics and pathogenesis to PD. The association between RA and PD has been investigated, and numerous publications on this subject exist. Approximately 20 bacterial species have been identified as periodontal pathogens, and these organisms are linked to various types of PD. The most analyzed species of periodontopathic bacteria are Porphyromonas gingivalis, Prevotella intermedia, Tannerella forsythia, and Aggregatibacter actinomycetemcomitans. Antibodies and DNA from these oral pathogens have been isolated from the sera and synovial fluids of RA patients. This rapid communication describes the role of periodontal pathogens in the etiopathogenesis of RA.
\end{abstract}

Keywords: etiopathogenesis, chronic arthritis, periodontitis, Porphyromonas gingivalis, systemic disease, animal models, antibiotics

\section{Introduction}

Rheumatoid arthritis (RA) is an autoimmune systemic disease that afflicts $0.5 \%-1 \%$ of the population worldwide. ${ }^{1}$ Periodontitis is characterized by infections that begin with an inflammation of the periodontium and progress to tooth loss. ${ }^{2}$ Untreated infections may destroy the periodontal ligament and alveolar bone. ${ }^{2}$ Periodontal disease (PD) is the most chronic infectious disorder, and its prevalence varies between $10 \%-60 \%$ in adults depending on the diagnostic criteria. ${ }^{2}$ PD includes gingivitis, which is an inflammation of the soft tissue surrounding the teeth, and periodontitis, which occurs with the spread of the disease to the alveolar bone. ${ }^{2}$

A significant increase in the incidence of PD has been observed in patients with chronic, active RA compared to healthy subjects, ${ }^{3}$ and the prevalence of RA is higher in PD patients compared to individuals without PD. ${ }^{3}$

Sulfasalazine was developed in Sweden for the treatment of RA 70 years ago. ${ }^{4}$ This drug contains a sulphonamide that was the most effective antibiotic of that period and has been proved efficacious in the treatment of RA. ${ }^{4}$ The mechanism of action of sulfasalazine may include alterations in the intestinal flora because decreased numbers of nonsporing anaerobes are observed in inflammatory bowel disease patients who are treated with sulfasalazine. ${ }^{5}$

Tetracyclines inhibit most periodontopathic bacteria in vitro and in vivo, ${ }^{6}$ and minocycline is effective for the treatment of RA and PD. ${ }^{6,7}$

We have demonstrated previously that clarithromycin and roxithromycin are effective against early and late disease-modifying antirheumatic drug (DMARD)-resistant RA. ${ }^{8-}$ 
${ }^{10}$ Roxithromycin and clarithromycin are used clinically in the treatment of anaerobic bacterial infections. ${ }^{8-10}$ The efficacy of these antibiotics is independent of RA severity, and the results are consistent with responses seen in anti-tumor necrosis factor (TNF) treated patients. ${ }^{8-10}$ Levofloxacin is also effective against RA. ${ }^{11}$

\section{Periodontal pathogens}

Approximately 20 bacterial species have been identified as periodontal pathogens, and these bacteria are associated with various types of PD. ${ }^{12}$ The most commonly studied periodontopathic bacteria include Porphyromonas gingivalis, Prevotella intermedia, Tannerella forsythia, and Aggregatibacter actinomycetemcomitans. ${ }^{12}$

$P$. gingivalis is a Gram-negative, asaccharolytic, anaerobic, nonmotile, nonsporing, short-rod microorganism that grows in brown- or black-pigmented colonies on blood agar. ${ }^{12}$ Some species that produce PD are abundant in the oral cavity ${ }^{12}$ and the upper gastrointestinal system, respiratory tract, and colon. ${ }^{12} P$. gingivalis possesses the highest proteolytic activity of the Gram-negative bacteria that have been isolated from PD-affected areas, and this species exhibits the highest virulence pattern in inoculated animals in a simple pathogenicity test. ${ }^{12} P$. gingivalis produces arginine-specific (gingipain R) and lysine-specific (gingipain K) cysteine endopeptidases. ${ }^{13}$ Various virulence factors, such as polysaccharide capsule, fimbriae, opsonin $\mathrm{C} 3$-associated proteases, IgG proteases, gingipains, bacterial lipopolysaccharides, toxins, and hemagglutinins, play a role in the persistence of $P$. gingivalis in the oral mucosa, which facilitates the appearance of certain physiopathological characteristics of chronic periodontitis. ${ }^{12}$

\section{Genetics of rheumatoid arthritis}

The strongest genetic association in RA is observed with the major histocompatibility complex class II, DR $\beta 1$ (human leukocyte antigen $[H L A]-D R \beta 1$ ) gene. This highly polymorphic gene encodes a cell surface molecule that is primarily expressed in antigen-presenting cells, such as dendritic cells, macrophages, and B cells. This molecule mediates the presentation of peptide antigens to $\mathrm{T}$ cells, which stimulates the cellular response to these antigens. Many variants of $H L A-D R \beta 1$ are associated with RA, and some variants are also associated with periodontitis. ${ }^{13}$ This association is due to five key amino acids on the side wall of the $H L A-D R \beta 1$ molecule (QK[R]RAA). This sequence is a shared epitope, and predisposition to the disease requires the presence of positively charged arginine and lysine residues at position 71 in the $H L A-D R \beta 1$ molecule. This positively charged motif sequence presents citrulline residue-containing peptides to T cells. ${ }^{13}$

In August 2001, Ogrendik et al hypothesized that $P$. gingivalis is an environmental factor that impairs tolerance against autoantigens that contain citrulline in a genetically susceptible host. ${ }^{13} P$. gingivalis is responsible for the severe forms of PD. ${ }^{12}$ This bacterium produces peptidyl arginine deiminase $(\mathrm{PAD})^{12}$ and can citrullinate the terminal arginine residues of peptides. ${ }^{13}$ Therefore, the chronic presence of these bacteria in inflamed periodontal tissue may induce the local production of citrullinated peptides. The microenvironment in chronic inflammatory oral lesions may be rich in proinflammatory cytokines, such as TNF- $\alpha$ and IL-1 $\beta$, which facilitates the presentation of citrullinated antigens to $\mathrm{T}$ cells by local antigen-presenting cells. The immune response in this environment shifts to homolog citrullinated human autoantigens, due to the molecular similarity and evolves. The ubiquitous enzyme enolase is a candidate antigen because a citrullinated form of enolase has been identified as an autoantigen in RA. ${ }^{14}$ The incubation of wild type $P$. gingivalis with fibrinogen or $\alpha$-enolase destroys these proteins and the citrullination of the carboxyl-terminal arginine residues. ${ }^{15} P$. gingivalis titration in RA patients is correlated with the concentration of anticitrullinated protein/ peptide antibodies. ${ }^{16}$

\section{Etiology of rheumatoid arthritis}

We observed higher serum levels of antibodies against disease-causing periodontal bacteria in RA patients compared to a control group in a case-control study ${ }^{13}$ and reported that anti- $P$. gingivalis antibodies were more frequently observed in RA patients than healthy controls. Furthermore, the concentrations of autoantibodies that are related to RA and C-reactive protein are also higher in people with $P$. gingivalis infections. This study was conducted from August 2001 to August 2002 in Turkey and Australia. ${ }^{13}$ Similar results have been demonstrated in other case-control studies. ${ }^{17}$

However, the detection of bacterial DNA, rather than antibodies, in the synovial fluid of RA patients is a more significant result because it indicates the transfer of bacterial DNA from the infection site into the joints. Recent studies have focused on the determination of bacterial DNA in the joints of RA patients, using checkerboard DNA-DNA hybridization or polymerase chain reaction (PCR) detections. ${ }^{18,19}$ P. gingivalis, T. forsythia, and P. intermedia bacteria have been determined in synovial fluid samples from patients with RA and psoriatic arthritis through the detection of checkerboard 
DNA-DNA hybridization. ${ }^{18}$ A recent cross-sectional study of 19 patients with periodontitis and resistant RA who received intensive therapy with DMARDs (eg, methotrexate, sulfasalazine, leflunomide, and chloroquine) demonstrated the presence of P. intermedia (89.4\%), P. gingivalis (57.8\%), and Prevotella nigrescens $(21.0 \%)$ using PCR. ${ }^{19}$ These two studies ${ }^{18,19}$ clearly support the presence of the chromosomal DNA of PD-associated bacteria in the sera and synovial fluid of RA patients. Synovial inflammation in RA facilitates the detection of oral bacterial DNA. ${ }^{18}$

PD patients frequently experience bacteraemic episodes. The frequency of bacteraemia is $13 \%$ after ultrasonic measurements; 20\% after periodontal interventions; and 3\% after tooth brushing. ${ }^{20}$ Periodontal pathogens can directly access the blood circulation, ${ }^{18,19}$ and periodontal bacterial DNA is transported from the periodontal regions to the synovium in the form of free DNA. ${ }^{19}$

\section{Animal models}

The association between $P$. gingivalis and RA has been investigated in animal models. The injection of heat-killed P. gingivalis into the backs of rats with RA stimulates arthritic development as measured by paw swelling. ${ }^{21}$ A P. gingivalisinduced extrasynovial, chronic inflammatory lesion noticeably stimulated the development of arthritis in this model. ${ }^{21}$ This same group examined preexisting PD and its effects on arthritis using a RA rat model. ${ }^{22}$ PD was precipitated using an oral gavage with $P$. gingivalis, and arthritis was initiated using the collagen antibody-induced arthritis model. The PD rats exhibited higher inflammation levels and more radiographic joint damage following arthritis compared to rats without PD. This study demonstrated that $P$. gingivalis-induced preexisting PD enhanced the formation and severity of arthritis. These results demonstrate that $\mathrm{PD}$ caused by bacterial infection increases inflammation in distant synovial tissues.

In another investigation, DR4 transgenic rats were immunized with enolase that was isolated from $P$. gingivalis to specify the relationship between RA characterized by anticitrullinated enolase peptide (anti-CEP) antibody positivity and $P$. gingivalis. ${ }^{23}$ The anti-CEP antibody is specific to $\mathrm{RA},{ }^{24}$ and it is largely associated with alleles that contain the $H L A-D R B 1$ shared epitope. ${ }^{24}$ This study demonstrated a more severe arthritis in the rats immunized with enolase (native and citrullinated forms) isolated from both humans and bacteria compared to the control group. Furthermore, immunization with $P$. gingivalis enolase generated autoimmunity to human alpha-enolase and promoted the progression of arthritis. These results suggest that enolase from $P$. gingivalis in its most native form precipitates the onset of RA in some patients.

\section{Conclusion}

Gram-negative anaerobic bacilli may cause infections anywhere in the body; the most common types are oral and dental, pleuropulmonary, intra-abdominal, female genital tract and skin, soft tissue and bone infections. ${ }^{25}$ In other words, it does not mean that the individuals with RA should have periodontitis also. Therefore, the above results indicate that periodontopathic bacteria are responsible for the etiopathogenesis of RA in a genetically susceptible host. These results will guide more comprehensive and efficacious treatment strategies for RA.

\section{Disclosure}

The authors report no conflicts of interest in this work.

\section{References}

1. Bax M, van Heemst J, Huizinga TW, Toes RE. Genetics of rheumatoid arthritis: what have we learned? Immunogenetics. 2011;63(8): 459-466.

2. Modi DK, Chopra VS, Bhau U. Rheumatoid arthritis and periodontitis: biological links and the emergence of dual purpose therapies. Indian J Dent Res. 2009;20(1):86-90.

3. Ogrendik M. Rheumatoid arthritis is linked to oral bacteria: etiological association. Mod Rheumatol. 2009;19(5):453-456.

4. Svartz N. The treatment of rheumatic polyarthritis with acid azo compounds. Rheumatism. 1948;4(1):180-185.

5. Das KM. Sulfasalazine therapy in inflammatory bowel disease. Gastroenterol Clin North Am. 1989;18(1):1-20.

6. Nakao R, Takigawa S, Sugano N, et al. Impact of minocycline ointment for periodontal treatment of oral bacteria. Jpn J Infect Dis. 2011;64(2): $156-160$.

7. Tilley BC, Alarcón GS, Heyse SP, et al. Minocycline in rheumatoid arthritis. A 48-week, double-blind, placebo-controlled trial. MIRA Trial Group. Ann Intern Med. 1995;122(2):81-89.

8. Ogrendik M. Effects of clarithromycin in patients with active rheumatoid arthritis. Curr Med Res Opin. 2007;23:515-522.

9. Ogrendik M. Efficacy of roxithromycin in adult patients with rheumatoid arthritis who had not received disease-modifying antirheumatic drugs: a 3-month, randomized, double-blind, placebo-controlled trial. Clin Ther. 2009;31(8):1754-1764.

10. Ogrendik M, Karagoz N. Treatment of rheumatoid arthritis with roxithromycin: a randomized trial. Postgrad Med. 2011;123(5): 220-227.

11. Ogrendik M. Levofloxacin treatment in patients with rheumatoid arthritis receiving methotrexate. South Med J. 2007;100(2):135-139.

12. Marsh PD, Martin MV. Oral Microbiology, 4th ed. Bodmin: MPG Books Ltd; 2001.

13. Ogrendik M, Kokino S, Ozdemir F, Bird PS, Hamlet S. Serum antibodies to oral anaerobic bacteria in patients with rheumatoid arthritis. MedGenMed. 2005;7(2):2.

14. Kinloch A, Tatzer V, Wait R, et al. Identification of citrullinated alphaenolase as a candidate autoantigen in rheumatoid arthritis. Arthritis Res Ther. 2005;7(6):R1421-R1429.

15. Wegner N, Wait R, Sroka A, et al. Peptidylarginine deiminase from Porphyromonas gingivalis citrullinates human fibrinogen and $\alpha$-enolase: implications for autoimmunity in rheumatoid arthritis. Arthritis Rheum. 2010;62(9):2662-2672. 
16. Hitchon CA, Chandad F, Ferucci ED, et al. Antibodies to Porphyromonas gingivalis are associated with anticitrullinated protein antibodies in patients with rheumatoid arthritis and their relatives. $J$ Rheumatol. 2010;37(6):1105-1112.

17. Okada M, Kobayashi T, Ito S, et al. Antibody responses to periodontopathic bacteria in relation to rheumatoid arthritis in Japanese adults. J Periodontol. 2011;82(10):1433-1441.

18. Moen K, Brun JG, Valen M, et al. Synovial inflammation in active rheumatoid arthritis and psoriatic arthritis facilitates trapping of a variety of oral bacterial DNAs. Clin Exp Rheumatol. 2006;24(6):656-663.

19. Martinez-Martinez RE, Abud-Mendoza C, Patiño-Marin N, Rizo-Rodríguez JC, Little JW, Loyola-Rodríguez JP. Detection of periodontal bacterial DNA in serum and synovial fluid in refractory rheumatoid arthritis patients. J Clin Periodontol. 2009;36(12): 1004-1010.

20. Kinane DF, Riggio MP, Walker KF, MacKenzie D, Shearer B. Bacteraemia following periodontal procedures. J Clin Periodontol. 2005;32(7):708-713.
21. Bartold PM, Marino V, Cantley M, Haynes DR. Effect of Porphyromonas gingivalis-induced inflammation on the development of rheumatoid arthritis. J Clin Periodontol. 2010;37(5):405-411.

22. Cantley MD, Haynes DR, Marino V, Bartold PM. Pre-existing periodontitis exacerbates experimental arthritis in a mouse model. J Clin Periodontol. 2011;38(6):532-541.

23. Kinloch AJ, Alzabin S, Brintnell W, et al. Immunization with Porphyromonas gingivalis enolase induces autoimmunity to mammalian $\alpha$-enolase and arthritis in DR4-IE-transgenic mice. Arthritis Rheum. 2011;63(12):3818-3823.

24. Mahdi H, Fisher BA, Källberg H, et al. Specific interaction between genotype, smoking, and autoimmunity to citrullinated alpha-enolase in the etiology of rheumatoid arthritis. Nat Genet. 2009;41(12): 1319-1324.

25. Finegold SM. Anaerobic Gram-negative bacilli. In: Baron S, editor. Medical Microbiology, 4th ed. Galveston, TX, USA: University of Texas Medical Branch at Galveston; 1996; chapter 20.
International Journal of General Medicine

\section{Publish your work in this journal}

The International Journal of General Medicine is an international, peer-reviewed open-access journal that focuses on general and internal medicine, pathogenesis, epidemiology, diagnosis, monitoring and treatment protocols. The journal is characterized by the rapid reporting of reviews, original research and clinical studies across all disease areas.

\section{Dovepress}

A key focus is the elucidation of disease processes and management protocols resulting in improved outcomes for the patient.The manuscript management system is completely online and includes a very quick and fair peer-review system. Visit http://www.dovepress.com/ testimonials.php to read real quotes from published authors. 